\title{
Development of a First Version of a Maturity Matrix for ICT4D Knowledge Repositories
}

\author{
Melanie PLATZ ${ }^{1}$, Judy VAN BILJON ${ }^{2}$ \\ ${ }^{1}$ University of Koblenz-Landau, Fortstr. 7, 76829 Landau, Germany \\ \& University of South Africa, Unisa Science Campus, Florida, Johannesburg, South Africa \\ Tel: +49(0)6341 28031 208, Fax: +49(0)634128031 385, Email: platz@uni-landau.de \\ ${ }^{2}$ University of South Africa, Unisa Science Campus, Florida, Johannesburg, South Africa \\ Tel: +27(0)11670 9182,Email:Vbiljja@unisa.ac.za
}

\begin{abstract}
Reputable Information and Communication Technology (ICT) for Development (ICT4D) collections focused on Sub-Saharan Africa exist but a platform where these silos of excellence can be aligned and shared for open access is not a reality yet. An open browser-based ICT4D knowledge repository (ICT4D-KR) is proposed as an initiative towards addressing the problem. Based on literature, a survey on the usefulness and functionality of a South African ICT4D knowledge repository $(S A-I C T 4 D-K R)$ and a category analysis of selected existing Knowledge Sharing Platforms (KSPs), a first proposal for an ICT4D-KR maturity matrix has been derived and is presented here.
\end{abstract}

Keywords: ICT4D, Knowledge Repository, Maturity Matrix, Open Source

\section{Introduction}

"Knowledge sharing is crucial because it enables people to capitalize on existing knowledge bases residing within and outside the organization, thus enhancing their capacity to come up with creative solutions, and enabling their organizations to develop new platforms for the development and introduction of new products and services to the market." - Carmeli et al. 2013, [1]

Especially in the field of ICT4D, it is crucial to communicate and share ideas and resources. To improve communication and ensure a solid foundation for future research sharing of the basic objectives, assumptions, central theories, models and frameworks of ICT4D is necessary. Therefore, an open knowledge repository (KR) where research agendas, methodologies, theories, models and frameworks are investigated and discussed for inclusion in an open ICT4D-KR is supposed to be developed. The goal is to create a platform where the already reputable ICT4D collections can be aligned and shared for open access. Platz \& Biljon [2] argue for an open SA-ICT4D-KR and confirmed the need in a survey by the majority of $84.21 \%$ of the probands ( $15.79 \%$ abstentions). To address the question on how it should be approached in order to meet the criteria of an open but organised and maintained KR, Platz \& Biljon [2] propose a first collection of the contents and the functionalities of an open browser-based ICT4D-KR. To extend this collection, the proposal of contents and functionalities was evaluated with a survey on the potential usefulness and desired functionality of a SA-ICT4D-KR and the contents and functionalities were adjusted. The ICT4D-KR could be hosted at a university or research institution, but a university is proposed to capitalise on structural university resources. It is 
a challenging objective for a university to develop a reliable and usable ICT4D-KR that is delivered fast and at low cost. A KR that is outdated, over budget, or that does not work as expected causes problems for the organization, but also for the users. Through a focused and sustained effort at building a process infrastructure of effective development and management practices, these problems can be approached (cf. Paulk et al. [3]). Paulk et al. [3] state, that an organization needs ways to appraise its ability to perform its processes successfully to build such a process infrastructure. Furthermore, guidance is needed to improve their process capability. As funding is a big issue at universities and not each task can be performed by the university staff, the university as prime contractor needs ways to evaluate the capability of potential subcontractors. To optimize and facilitate the development process for an ICT4D-KR, an ICT4D-KR maturity matrix is developed as basis for the development of an ICT4D-KR maturity model that delineates the characteristics of a mature, capable development process.

\section{Methodology}

\subsection{Objectives}

The main challenge is to foster and facilitate practical knowledge sharing in ICT4D - from data sharing to collaboration. Developing an instrument to evaluate the sophistication of a technological platform has no value if adoption and use of the platform is not attended to first.

Therefore, the following question is explored in this study: How can an inclusive ICT4D knowledge repository be developed? An architecture for the comprehensive inclusion of different ICT4D research groups in an ICT4D-KR has to be developed to reach the goal of a platform where reputable ICT4D collections can be aligned and shared. The current scope is South Africa but the idea is to extend this for sub-Saharan Africa. Therefore, a generative method has to be developed. The architecture for the KR should support collaboration between ICT4D research groups, practitioners and communities. Subgroups working on the different aspects of the KR as informed by the architecture have to be created and the contributions of the sub-groups have to be evaluated constantly. Awareness of potential usefulness of the KR has to be raised, e.g. via presentations on conferences or articles in popular journals. To optimise the KR, knowledge on African tradition and culture should be captured continuously as this knowledge relates to ICT development.

As a preliminary step towards the development of an ICT4D-KR, an ICT4D-KR maturity matrix will be proposed in this paper to be able to derive a ICT4D-KR maturity model in future research to determine the maturity of an ICT4D-KR and to start the development of an ICT4D-KR. In the present study, the maturity model is not understood as instrument to evaluate the sophistication of a technological platform, but as a preliminary design guideline to enable a potentially quick and appropriate development of an ICT4DKR for adoption and use of the ICT4D-KR.

Consequently, an ICT4D-KR maturity matrix is developed as basis for the development of an ICT4D-KR maturity model that delineates the characteristics of a mature, capable development process to optimize and facilitate the development process. The basis of the ICT4D-KR maturity matrix is the extended, refined and adjusted collection of the contents and the functionalities of an open browser-based ICT4D-KR by Platz \& Biljon [2] through the evaluation of a survey on the potential usefulness and desired functionality of a SAICT4D-KR. 


\subsection{Strategy}

The initial architecture of an ICT4D-KR maturity matrix was compiled from literature and refined by considering several existing ICT4D-KRs and a survey on the usefulness and functionality of a $S A-I C T 4 D-K R$. An ICT4D-KR maturity model differs from existing maturity models, because an $I C T 4 D-K R$ is a hybrid of different web-applications or platforms. Therefore, a new maturity model has to be developed, which can be composed by adapting existing maturity models in other fields, among others.

\section{Knowledge Repository Development}

To identify the key aspects that impact the design, uptake and usage of a KR, a sociotechnical analysis is required for the development of an ICT4D-KR. Lwoga et al., [4] used an exploratory survey, system analysis and ICT-based design as methodologies to convey the current state of knowledge sharing activities and assess the user requirements. A similar process is followed for the development of the ICT4D-KR. Foth, Gonzalez \& Kraemer, [5], proposed a model consisting of the following three layers for understanding key aspects that impact the design, uptake and usage of a $\mathrm{KR}$ in an information portal: a technological layer, a social layer and a discursive layer.

- Technological Layer: The ICT4D-KR should be freely accessible via several digital devices. For the KR, the import and export of data (i.e. knowledge) in several data formats should be enabled. Additionally, a possibility to use the open ICT4D-KR offline should be implemented, as internet connection is not available everywhere. In the online-version, a platform for discussions should be integrated.

- Social Layer: The goal is to develop an open ICT4D-KR. Therefore, an analysis of the socio-economic-, cultural- and ICT-situation of the target group needs to be done as well as a software analysis.

- Discursive Layer: The portal designs have to fulfil different needs for different users at different times. Foth et al., [5], sees variability and diversity as crucial advantages and introduced communicative ecology as conceptual response to the challenge of taking variability and diversity into account. In order to face the challenge of taking variability and diversity into account in our case and in order to reach as many potential users as possible and to enable the collaboration of several different user groups, an adaptive Graphical User Interface (GUI) is proposed for the open ICT4D-KR (cf. Platz \& Biljon [2]).

As starting point for the development of an SA-ICT4D-KR, Platz \& Biljon [2] proposed a first collection of the contents and the functionalities of an open browser-based ICT4D$K R$. To extend and refine this collection, the proposal of contents and functionalities was evaluated with a survey on the potential usefulness and desired functionality of a $S A$ $I C T 4 D-K R$ and the contents and functionalities were adjusted. Departing from that set of contents and functionalities, 16 ICT4D-KRs were analysed and the collection of functionalities was updated and grouped according to their purpose (see Figure 1). The KRs were selected by starting with South African university ICT4D sites and extended to include sites from international ICT4D research organisations. The selection and addition process was terminated when two consecutive new sites did not add any new features or functionality. 


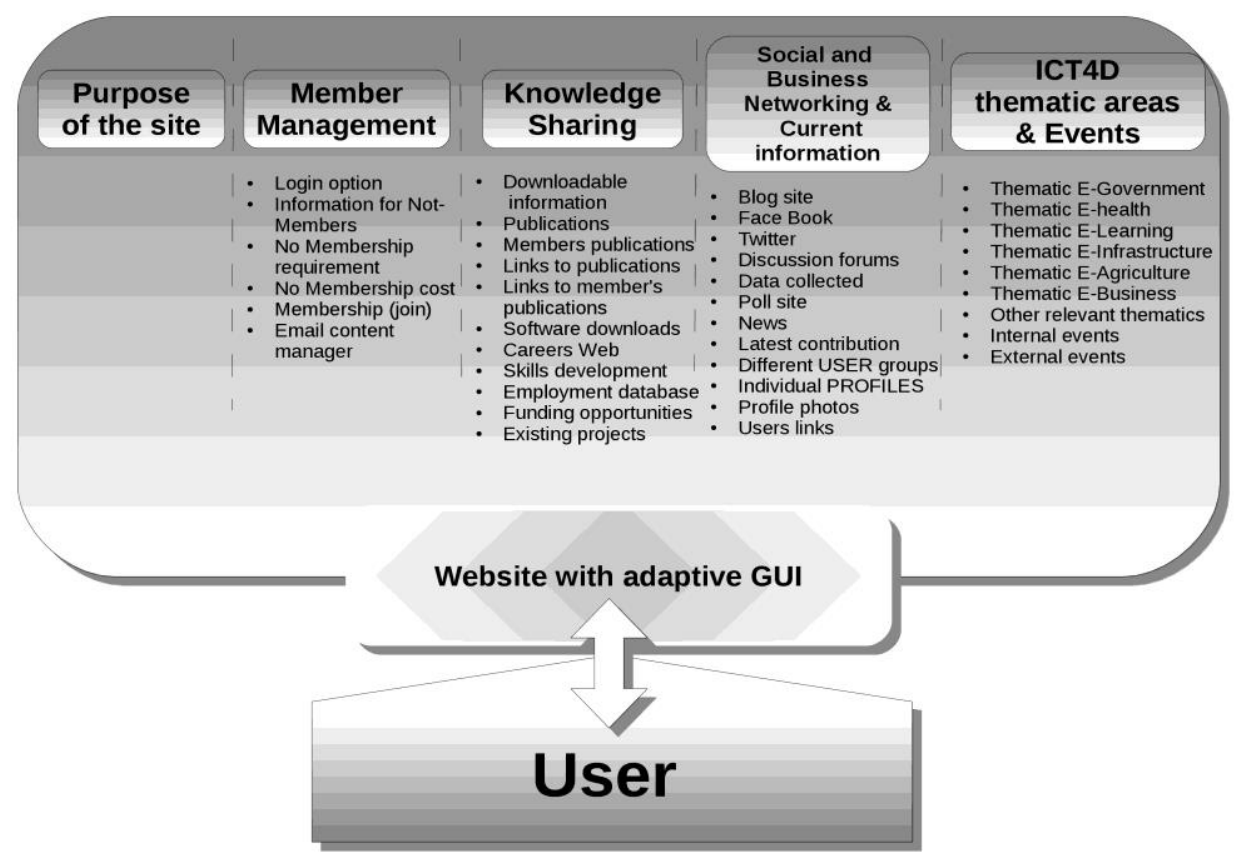

Figure 1: ICT4D-KR Category Items

To optimize and facilitate the development process, an ICT4D-KR maturity matrix is developed as basis for the development of an ICT4D-KR maturity model that delineates the characteristics of a mature, capable development process.

\section{Proposed ICT4D KR Maturity Matrix}

According to Klimko, [6], a maturity model describes the development of an entity over time. It has the following properties:

- "The development of a single entity is simplified and described with a limited number of maturity levels (usually four to six).

- Levels are characterized by certain requirements which the entity has to achieve on that level.

- Levels are sequentially ordered, from an initial level up to an ending level (the latter is the level of perfection).

- During the development the entity is progressing forwards from one level to the next one. No level can be left out." (Klimko, [6])

There are different ways to perform maturity modelling. For example, the Maslow hierarchy assumes that the entity is a human who progresses through the pyramid of needs, starting from physiological needs up to self-actualization needs. The capability maturity model for software development assumes that quality can be cultivated through control; the entity is the software development function (cf. Klimko, [6]).

Currently, no maturity model for KRs exists. To optimize and facilitate the development process of an ICT4D-KR, an ICT4D-KR maturity matrix is developed in this article as basis for the development of an ICT4D-KR maturity model that delineates the characteristics of a mature, capable development process. Therefore, a maturity matrix for ICT4D-KRs is proposed in the following. To be able to develop a suitable ICT4D-KR maturity matrix, existing maturity models have to be adapted and composed. The result will be a hybrid maturity matrix which is adjusted to ICT4D-KRs.

Capability Maturity Model. As the ICT4D-KR will be provided in the form of a webapplication, we can refer to the capability maturity model for software in order to derive 
maturity levels for the overall development process. Paulk et al. [3], developed a capability maturity model for software (here: expanded with Rhoads [7]). The maturity model is adapted to the requirements of an ICT4D-KR (Table 1).

Table 1: Capability Maturity Model (Paulk et al. [3] \& Rhoads [7]) Adapted to the Requirements of an ICT4D-KR.

\begin{tabular}{|c|c|c|c|c|}
\hline Level & $\begin{array}{l}\text { Denomination } \\
\text { (Paulk et al. [3] \& } \\
\text { Rhoads [7]) }\end{array}$ & Description & Key Process Areas ICT4D-KR & $\begin{array}{l}\text { Key Process Areas in Paulk et al. } \\
\text { [3] (Capability maturity model for } \\
\text { software) }\end{array}$ \\
\hline 1 & Initial & $\begin{array}{l}\text { Ad hoc, no control } \\
\text { (Rhoads [7]) }\end{array}$ & \multicolumn{2}{|l|}{-} \\
\hline \multirow[t]{2}{*}{2} & \multirow[t]{2}{*}{ Repeatable } & \multirow[t]{2}{*}{$\begin{array}{l}\text { Disciplined process } \\
\text { (Paulk et al. [3]) }\end{array}$} & $\begin{array}{l}\text { ICT4D-KR configuration management, } \\
\text { ICT4D-KR quality assurance, } \\
\text { ICT4D-KR subcontract management, } \\
\text { ICT4D-KR project tracking and oversight, } \\
\text { ICT4D-KR project planning }\end{array}$ & $\begin{array}{l}\text { Software configuration management } \\
\text { Software quality assurance } \\
\text { Software subcontract management } \\
\text { Software project tracking and } \\
\text { oversight } \\
\text { Software project planning }\end{array}$ \\
\hline & & & \multicolumn{2}{|c|}{ Requirements management } \\
\hline \multirow[t]{2}{*}{3} & \multirow[t]{2}{*}{ Defined } & \multirow{2}{*}{$\begin{array}{l}\text { Standard, consistent } \\
\text { process (Paulk et al. } \\
[3]) \text { : } \\
\text { Consistent } \\
\text { implementation, } \\
\text { improved understanding } \\
\text { of the process (Rhoads } \\
[7])\end{array}$} & $\begin{array}{l}\text { ICT4D-KR product engineering, } \\
\text { Integrated ICT4D-KR management, } \\
\text { University process definition, } \\
\text { University process focus }\end{array}$ & $\begin{array}{l}\text { Software product engineering } \\
\text { Integrated software management } \\
\text { Organization process definition } \\
\text { Organization process focus }\end{array}$ \\
\hline & & & $\begin{array}{r}\text { Peer revi } \\
\text { Intergroup coo } \\
\text { Training pr }\end{array}$ & $\begin{array}{l}\text { ews, } \\
\text { rdination, } \\
\text { ogram }\end{array}$ \\
\hline \multirow[t]{2}{*}{4} & \multirow[t]{2}{*}{ Managed } & \multirow{2}{*}{$\begin{array}{l}\text { Predictable process } \\
\text { (Paulk et al. [3]) }\end{array}$} & ICT4D-KR Quality management & Software Quality management \\
\hline & & & \multicolumn{2}{|c|}{ Quantitative Process measurement } \\
\hline 5 & Optimizing & $\begin{array}{l}\text { Continuously improving } \\
\text { process (Paulk et al. } \\
[3]): \\
\text { a foundation is } \\
\text { established for the } \\
\text { continued improvement } \\
\text { and optimization of } \\
\text { process (Rhoads [7]) }\end{array}$ & $\begin{array}{r}\text { Process change } \mathrm{m} \\
\text { Technology change } \\
\text { Defect prev }\end{array}$ & $\begin{array}{l}\text { nanagement, } \\
\text { e management, } \\
\text { vention }\end{array}$ \\
\hline
\end{tabular}

Knowledge Management Maturity Model. Knowledge management is essential within a KR (Garfield [8]; Korvela [9]). The system should be easy to use and social incentives could be useful to promote use (Dingsoyr \& Royrvik [10]). Klimko [6] proposes a maturity model for knowledge management. The maturity model of Klimko [6] for knowledge management focuses on business. As the ICT4D-KR is supposed to be open, the focus has to be shifted to the institution university and non-profit. The maturity model is adapted to the requirements of an ICT4D-KR (Table 2). 
Table 2: Knowledge Management Maturity Model (Klimko [6]) adapted to the requirements of an ICT4D-KR. The bold marked items and terms differ from the model presented in Klimko [6].

\begin{tabular}{|c|c|c|c|c|c|c|c|}
\hline Level & $\begin{array}{l}\text { Denomi- } \\
\text { nation }\end{array}$ & Description & Focus & Key Processes & Challenge & Tool & Pitfall \\
\hline 1 & Initial & $\begin{array}{l}\text { Not paying any specific } \\
\text { attention to knowledge } \\
\text { management activities }\end{array}$ & - & - & - & - & - \\
\hline 2 & $\begin{array}{l}\text { Knowledge } \\
\text { Discoverer }\end{array}$ & $\begin{array}{l}\text { Define knowledge, } \\
\text { Scan available knowledge, } \\
\text { Codify knowledge, } \\
\text { Distribute knowledge }\end{array}$ & \begin{tabular}{|l|} 
Scanning \\
existing \\
internal and \\
external \\
knowledge
\end{tabular} & $\begin{array}{l}\text { Scanning, } \\
\text { Appraising, } \\
\text { Capturing, } \\
\text { Transferring }\end{array}$ & $\begin{array}{l}\text { Codification, } \\
\text { Transfer }\end{array}$ & Technical & $\begin{array}{l}\text { Wrong } \\
\text { Appraisal, } \\
\text { Dependence } \\
\text { on } \\
\text { Technology }\end{array}$ \\
\hline 3 & $\begin{array}{l}\text { Knowledge } \\
\text { Creator }\end{array}$ & $\begin{array}{l}\text { Focus on externals (Users), } \\
\text { Management commitment, } \\
\text { Understand user needs, } \\
\text { Innovate }\end{array}$ & $\begin{array}{l}\text { Creation of } \\
\text { new } \\
\text { knowledge }\end{array}$ & $\begin{array}{l}\text { Commitment, } \\
\text { Understanding user } \\
\text { needs, Innovation }\end{array}$ & $\begin{array}{l}\text { Understanding } \\
\text { the } \\
\text { environment } \\
\text { and the trends }\end{array}$ & $\begin{array}{l}\text { Non- } \\
\text { Technical }\end{array}$ & $\begin{array}{l}\text { Waste of } \\
\text { resources }\end{array}$ \\
\hline 5 & $\begin{array}{l}\text { Knowledge } \\
\text { Renewer }\end{array}$ & $\begin{array}{l}\text { Share with alliances; } \\
\text { Improve continuously }\end{array}$ & $\begin{array}{l}\text { Inter- } \\
\text { organizational } \\
\text { cooperation }\end{array}$ & Sharing & $\begin{array}{l}\text { Achieve } \\
\text { confidence }\end{array}$ & $\begin{array}{l}\text { Non- } \\
\text { Technical }\end{array}$ & Vulnerability \\
\hline
\end{tabular}

Web Maturity Model. As the ICT4D-KR will be presented as website, the web maturity model suggested by Rhoads [7] (here: expanded with Fath-Allah et al. [11]) will be adjusted through adapting the content-categories derived from Platz \& Biljon [2] and the analysis of 16 existing ICT4D-KRs. The content-categories for an ICT4D-KR are visualized in Figure 1. In the following, the web maturity model is adapted to the requirements of an ICT4D-KR.

An ICT4D-KR maturity matrix can be composed from the three considered maturity models as depicted in Table 4. The maturity matrix in Table 4 is constructed in the following way:

Level 1: The categories capability, knowledge management and web are in the initial state: There is no control over the system, knowledge management activities did not start yet and the ICT4D-KR is present, general information like the purpose of the site is available.

Level 2: The starting point for development is capability: The process is disciplined, $I C T 4 D-K R$ configuration management, ICT4D-KR quality assurance, ICT4D-KR subcontract management, ICT4D-KR project tracking and oversight, ICT4D-KR project planning, and requirements management are done. Knowledge management and web are still in the initial state. It is important to start with capability, because the planning of the whole development procedure is essential before next steps can be done.

Level 3: The next issue is knowledge discovery: Existing ICT4D-knowledge in the hosting university and external knowledge is scanned. Therefore, ICT4D-knowledge is defined, available ICT4D-knowledge is defined, the knowledge is codified and the knowledge is distributed. The Repository is still in the initial state, capability in repeatable state. It is important to continue with knowledge discovery, because this way content for the ICT4D$K R$ presented on a website can be created.

Level 4: The next step is web information processing: Some of discovered knowledge (Level 3) is processed and the ICT4D-KR is updated with the gained knowledge. Information or content like ICT4D news and project news are added to the ICT4D-website, as well as university-external and university-internal events. The ICT4D-KR is updated with links to ICT4D-publications and contents. Furthermore, an option to follow the project on Facebook and Twitter is offered. Feedback mechanisms are included via the possibility to 
e-mail the $I C T 4 D-K R$ content manager. Knowledge discovery is continued and capability is still in the repeatable state.

Table 3: Web Maturity Model (Rhoads [7] \& Fath-Allah et al. [11]) adapted to the requirements of an ICT4D-KR. The bold marked items and terms differ from the models presented in Rhoads [7] \& Fath-Allah et al. [11].

\begin{tabular}{|c|c|c|}
\hline Level & Denomination & Description (cf. Rhoads [7]) \\
\hline 1 & Presence (Rhoads [7]) & Online availability of general information: Purpose of the site \\
\hline 2 & $\begin{array}{l}\text { Information Processing (Rhoads } \\
\text { [7]) } \\
\text { (Interaction Fath-Allah et al. } \\
\text { [11]) }\end{array}$ & $\begin{array}{l}\text { Content/ Information (text and graphics): } \\
\text { - News } \\
\text { - External/ Internal events } \\
\text { Products (in our case: knowledge/ information): } \\
\text { - Links to publications/ content } \\
\text { Contact information, directions: } \\
\text { - Face Book } \\
\text { - Twitter } \\
\text { Feedback mechanisms, e-mail content manager }\end{array}$ \\
\hline 3 & $\begin{array}{l}\text { Knowledge Creation (Rhoads } \\
\text { [7]) } \\
(\text { Transaction ( Fath-Allah et al. } \\
[11]) \text { ) }\end{array}$ & $\begin{array}{l}\text { Defined taxonomy; } \\
\text { Search engine technology; } \\
\text { Online catalogues: } \\
\text { - Downloadable information } \\
\text { - Publications } \\
\text { - Software downloads } \\
\text { - Careers Web } \\
\text { - Skills development } \\
\text { - Employment database } \\
\text { - Funding opportunities } \\
\text { - Existing projects } \\
\text { - Latest contributions } \\
\text { online fulfilment; } \\
\text { training program (skills development) } \\
\text { defined usage statistics strategy; }\end{array}$ \\
\hline 4 & $\begin{array}{l}\text { Project value clearly identified } \\
\text { and derived (cf. Rhoads [7]) } \\
\text { (Integration (Fath-Allah et al. } \\
[11]))\end{array}$ & $\begin{array}{l}\text { Content management strategy; } \\
\text { Content management system implementation; } \\
\text { Caching distribution management; } \\
\text { Ability to secure, free password protect areas within the site: } \\
\text { - Login option } \\
\text { - No Membership requirement } \\
\text { - No Membership cost } \\
\text { - Members' publications / Links to members' publications } \\
\text { A costumer relationship management strategy } \\
\text { - Blog Site } \\
\text { - Discussion forums } \\
\text { - Data collected } \\
\text { - Poll site }\end{array}$ \\
\hline 5 & $\begin{array}{l}\text { True Excellence through an } \\
\text { Integrated, Personalized and } \\
\text { Collaborative environment } \\
\text { (Rhoads [7]) } \\
\text { (Personalization ( Fath-Allah et } \\
\text { al. [11])) }\end{array}$ & $\begin{array}{l}\text { Portal capabilities: } \\
\text { - Different USER groups } \\
\text { - Individual PROFILES } \\
\text { - Profile photos } \\
\text { - Users links } \\
\text { Personalization capabilities; } \\
\text { Deployment of multiple types of content (files included in multiple languages and formats) }\end{array}$ \\
\hline
\end{tabular}

Level 5: The ICT4D-KR is developed further - the next step is web knowledge creation: The taxonomy of the ICT4D-KR is defined. ICT4D-online catalogues with downloadable ICT4D-information, ICT4D-publications, software downloads related to ICT4D, careers web in the field of ICT4D, ICT4D skills development, ICT4D employment database, ICT4D funding opportunities and existing ICT4D projects are generated with a search option. A date-attribute is assigned to the catalogue entries and the most current entries or latest contributions are shown on the web-site. A training program for the persons working on the page is offered to optimize the content creation for the web-site. A usage statistics strategy is defined.

Level 6: The next capability level - defined - is reached. The current processes and the system is peer reviewed and optimized, if necessary. The group working on the project are 
coordinated. ICT4D-KR product engineering is done as well as integrated ICT4D-KR management. The working group from the hosting university defines further processes and the process focus. The result is a standard, consistent process with consistent implementation and improved understanding of the process.

Level 7: The ICT4D- KR is developed further - the next step is web project value identified: A first content management strategy is developed and a pilot content management system is implemented (will be revised in Levels 10 and 11). Caching distribution is managed. The ability to secure, free password protect areas within the site is offered. There is no membership requirement and no membership cost. As a member, own publications or links to own publications can be uploaded and accessed from other members. A costumer relationship management strategy is developed. In this context, a blog site, discussion forums, poll sites are added and data collections for improving the ICT $4 D-K R$ are performed.

Level 8: The next issue is knowledge creation. New knowledge is created by the ICT4D$K R$ members and the working group from the hosting university. Therefore, innovation is important. The focus is on the users. For appropriate knowledge creation, the ICT4D user needs have to be understood. A first knowledge management commitment is done, which is elaborated in Levels 10 and 11.

Level 9: The ICT4D-KR is developed further - the next step is integrated, personalized \& collaborative web environment: Portal capabilities are added with different ICT4D user groups (e.g. student, researcher, industry worker). Individual profiles can be generated with an optional profile photo and the option to present ICT4D-skills, ICT4D-KR contributions, ICT4D links, ICT4D-job/ -training/ -service/... offers etc. In the portal, personalization capabilities are included. Multiple types of content are present on the ICT4D-KR (text-files, video). If possible, the files are included in multiple languages and formats.

Level 10: The next issue is knowledge management. Resources are allocated in an optimal way. The knowledge management is institutionalized, the processes are documented, knowledge sharing is promoted, the resources are managed and sophisticated technology is utilized for optimal ICT4D-knowledge management.

Level 11: The next capability level - managed - is reached. ICT4D-KR quality management is done, as well as quantitative process measurement. The process is predictable.

Level 12: The next issue is knowledge renewal. Inter-organizational cooperation is established. The ICT4D-knowledge is share with alliances, the knowledge has to be improved continuously.

Level 13: The next capability level - optimizing - is reached. Process change management and technology change management is implemented, defects are prevented. The process is continuously improved by establishing a foundation for the continued improvement and optimization of the process. 
Table 4: Proposed ICT4D-KR Maturity Matrix.

\begin{tabular}{|l|l|l|l|}
\hline Level & $\begin{array}{l}\text { Capability Maturity Level } \\
\text { Denomination }\end{array}$ & $\begin{array}{l}\text { Knowledge Management } \\
\text { Maturity Level Denomination }\end{array}$ & $\begin{array}{l}\text { Web Maturity Level } \\
\text { Denomination }\end{array}$ \\
\hline $\mathbf{1}$ & Initial & Initial & Initial \\
\hline $\mathbf{2}$ & Repeatable & Initial & Initial \\
\hline $\mathbf{3}$ & Repeatable & Knowledge Discoverer & Initial \\
\hline $\mathbf{4}$ & Repeatable & $\begin{array}{l}\text { Knowledge Discoverer } \\
\text { Knowledge Discoverer }\end{array}$ & Interaction \\
\hline $\mathbf{5}$ & Repeatable & Kransaction \\
\hline $\mathbf{6}$ & Defined & Knowledge Discoverer & Transaction \\
\hline $\mathbf{7}$ & Defined & Knowledge Creator & Integration \\
\hline $\mathbf{8}$ & Defined & Knowledge Creator & Integration \\
\hline $\mathbf{9}$ & Defined & Knowledge Manager & Personalization \\
\hline $\mathbf{1 0}$ & Defined & Knowledge Manager & Personalization \\
\hline $\mathbf{1 1}$ & Managed & Knowledge Renewer & Personalization \\
\hline $\mathbf{1 2}$ & Managed & Knowledge Renewer & Personalization \\
\hline $\mathbf{1 3}$ & Optimizing & & \\
\hline & & &
\end{tabular}

\section{Business Benefits}

The concept of Open Community is used as measure and draft strategy for a participative communication and an efficient knowledge management. Open Community is a generalisation of the concept of OS to other collaborative effort. The term "open" for an open community refers to the opportunity for anyone to join and contribute to the collaborative effort. The direction and goals are determined collaboratively by all members of the community. The resulting work ("product") is made available under a free license, so that other communities can adapt and build on them, Niehaus, [12]. Using this concept, already developed components of OS software and Open Content can be modified and adjusted for the development of an application. The advantage is faster development, improvement and distribution of the application. The application can be provided free of charge.

\section{Future Work}

The next step is to test the suggested maturity model by investigating, if existing ICT4D$K R s$ and KSPs can be categorized with the maturity model. If necessary, the maturity model should be extended and adapted. An extension could be realized by reviewing more maturity models for other fields and incorporating them into the maturity model. When the maturity model is declared as suitable, the development process of the ICT4D-KR should start following the maturity levels. During the development the maturity model should be adjusted and updated, if necessary. As a first step towards development, a Product Requirements Document (PRD) should be developed based on the requirements and constraints of the open ICT4D-KR. From this PRD the requirements to the software tools and hardware tools can be derived and a software analysis to identify already existing OS software that can be used directly or in a modified way for the creation of the open ICT4D$K R$ can be performed. An open browser-based prototype for an open browser-based ICT4D$K R$ should be created. Further surveys on the quality of the prototype of the open ICT4D$K R$ should be performed. Based on the results, the prototype should be optimised and an improved version should be tested in an empirical study with pre-test, post-test and followup-test. 


\section{Conclusions}

In this article, a first proposal for an ICT4D-KR maturity matrix was derived based on a literature study, a survey on the usefulness and functionality of a South African ICT4D knowledge repository (SA-ICT4DKR) presented in Platz \& van Biljon [2] and a category analysis of selected existing KSPs. As a preliminary step towards the development of an $I C T 4 D-K R$, an ICT4D-KR maturity matrix is proposed in this paper to be able to derive a $I C T 4 D-K R$ maturity model in future research to determine the maturity of an ICT4D-KR and to start the development of an ICT4D-KR. In the present study, the maturity model is not understood as instrument to evaluate the sophistication of a technological platform, but as a preliminary design guideline to enable a potentially quick and appropriate development of an ICT4D-KR for adoption and use of the ICT4D-KR.

Consequently, an ICT4D-KR maturity matrix is developed as basis for the development of an ICT4D-KR maturity model that delineates the characteristics of a mature, capable development process to optimize and facilitate the development process.

The ICT4D-KR maturity matrix will be optimized in future research and an ICT4D-KR maturity model will be derived. Based on this model, the development process of an $I C T 4 D-K R$ prototype can be optimized and facilitated. The initial prototype of the ICT4D$K R$ will be designed for the South African research community. Transferability cannot be assumed therefore evaluation and related customisation would be required to make the contents meaningful to the wider Sub-Saharan community. By taking the development of an open ICT4D-KR further, the ideal of a platform where reputable ICT4D collections focused on Sub-Saharan Africa can be aligned and shared, can become a reality.

\section{References}

[1] Carmeli, A., Gelbard, R. and Reiter- Palmon, R., 2013. Leadership, Creative Problem- Solving Capacity, and Creative Performance: The Importance of Knowledge Sharing. Human Resource Management, 52(1), pp.95-121.

[2] Platz, M. and Van Biljon, J., 2015, May. Design of an open ICT4D knowledge repository. In ISTAfrica Conference, 2015 (pp. 1-11). IEEE.

[3] Paulk, M.C., Curtis, B., Chrissis, M.B. and Weber, C.V., 1993. Capability maturity model, version 1.1. Software, IEEE, 10(4), pp.18-27.

[4] Lwoga, E., Forzi, T., Laing, P. \& Mjema, E. (2006). KM in the agricultural field: an ICT-based approach to promote the development and sharing of knowledge among agricultural researchers in Africa. IST-AFRICA Confererence.

[5] Foth, M., Gonzalez, V. M. \& Kraemer, K. L. (2008). Design Considerations for Community Portals in Master-Planned Developments in Australia and Mexico. Paper presented at the OZCHI, December 812, Cairns, QLD, Australia.

[6] Klimko, G., 2001, November. Knowledge management and maturity models: building common understanding. In Proceedings of the Second European Conference on Knowledge Management. Bled, Slovenia (pp. 269-278).

[7] Rhoads, V., 2008, April 13. Web Maturity Models. IA SUMMIT 2008. http://www.slideshare.net/vtrhoads/web-maturity-models, retrieved:15/01/2016.

[8] Garfield, M. (2014) "Proposing a Knowledge Management System (KMS) Architecture to Promote Knowledge Sharing Among Employees", Twenty Second European Conference on Information Systems (ECIS) Proceedings, Tel Aviv 2014, pp. 1-13.

[9] Korvela, H. (2013) "Plz Urgent Help Needed !1!! - Aspects of On-Line Knowledge Sharing in EndUser Development Support", Proceedings of the Nineteenth Americas Conference on Information Systems, Chicago, Illinois, 15-17 August 2013, pp. 1-10.

[10] Dingsoyr, T. and E. Royrvik (2003) "An Empirical Study of an Informal Knowledge Repository in a Medium-Sized Software Consulting Company", Proceedings of the 25th International Conference on Software Engineering, May 2003. IEEE Computer Society, pp. 84-92.

[11] Fath-allah, A., L. Cheikhi, R. E. Al-qutaish and A. Idri (2014) "E-Government Maturity Models", International Journal of Software Engineering \& Applications (IJSEA), May 2014, 5(3), pp. 71-91.

[12] Niehaus, E., Definition: Open Community - Action Team 6 Follow-Up Initiative. http://at6fui.weebly.com/open-community-approach.html, retrieved:16/01/2016. 